\title{
Susceptibility of Wheat to Tilletia indica During Stages of Spike Development
}

\author{
Blair J. Goates and Eric W. Jackson
}

U.S. Department of Agriculture-Agricultural Research Service, 1691 S. 2700 W., Aberdeen, ID 83210.

Accepted for publication 26 March 2006.

\begin{abstract}
Goates, B. J., and Jackson, E. W. 2006. Susceptibility of wheat to Tilletia indica during stages of spike development. Phytopathology 96:962-966.

Karnal bunt of wheat is caused by the fungus Tilletia indica, which partially converts kernels into sori filled with teliospores. Despite minor overall yield and quality losses, the disease is of considerable international quarantine concern. Plant development stages reported susceptible to infection vary considerably. A study was designed to better define the susceptibility period by inoculating wheat spikes at different growth

dough. Spikes became susceptible only after emerging from the boot and continued to be susceptible up to soft dough stage at which low levels of disease occurred. Disease severity in both cultivars peaked when spikes were inoculated after complete emergence, but before the onset of anthesis. Disease levels tapered off gradually in spikes inoculated after anthesis. The results broaden the known susceptibility period of wheat to $T$. indica to include stages long after anthesis, and indicate that infection from airborne inoculum is not possible during boot or awns emerging stages, which are commonly referred to as the most susceptible stages.
\end{abstract} stages with naturally liberated secondary sporidia under optimal conditions for disease development. Spikes of a resistant and susceptible cultivar were inoculated at eight growth stages from awns emerging to soft
Additional keywords: smut, Triticum aestivum.
Karnal bunt of wheat is caused by the smut fungus Tilletia indica Mitra (=Neovossia indica) which typically causes partial conversion of individual kernels into sori filled with fetid teliospores affecting yield and quality (26). Commonly, only some kernels in a spike are affected. Kernels are infected locally rather than via systemic seedling infection as in the other wheat bunts caused by $T$. controversa, T. laevis, and T. tritici. Kernels typically have varying degrees of disease severity ranging from small point infections at the embryo end to infections that expand into the kernel groove and rarely convert the entire kernel into a dark mass of teliospores. Disease incidence varies considerably from year to year due to its dependence on favorable weather during heading $(5,12,13,25,28)$. Initial infection is favored by a period of relatively cool temperatures of approximately 20 to $25^{\circ} \mathrm{C}$ maximum and 8 to $10^{\circ} \mathrm{C}$ minimum $(2,13,28)$, in conjunction with high relative humidity often provided by rainfall which allows secondary sporidia in the canopy (4) to increase to concentrations sufficient to cause disease.

Since 1982, when Karnal bunt was intercepted in the United States in wheat originating from Mexico (23), the disease has caused considerable international quarantine concern despite minor overall yield and quality losses in countries where it occurs $(8,25,28)$. This concern increased dramatically in 1996 when Karnal bunt was first discovered in wheat fields in the United States (32).

After the initial recognition of $T$. indica as a distinct pathogen species in 1931 (19), Mitra (20) and Mundkur (21) conducted extensive inoculation experiments over several years but failed to induce the disease. They primarily inoculated seed or soil with teliospores, which reliably induce common bunt caused by $T$. laevis

Corresponding author: B. J. Goates; E-mail address: bgoates@uidaho.edu

DOI: 10.1094/PHYTO-96-0962

This article is in the public domain and not copyrightable. It may be freely reprinted with customary crediting of the source. The American Phytopathological Society, 2006 and T. tritici (15). Mundkur finally induced Karnal bunt by vacuum-infiltrating emerged spikes with teliospores (22) which demonstrated the locally infecting nature of $T$. indica for the first time. Mundkur mentioned that using sporidia as inoculum in his experiments would have probably worked even better, and he correctly postulated that airborne sporidia originating from teliospores germinating at the soil surface infect florets locally to cause Karnal bunt in nature. This discovery was followed by several classical experiments by Bedi et al. (5) that proved Mundkur's hypothesis. During the late 1980s, the histological details of local infection and disease development were described $(9,14)$.

Because favorable weather for disease coinciding with wheat heading can be rare in most years in areas where Karnal bunt occurs, artificial inoculation is used to screen germplasm. The original work of Bedi et al. (5) laid the foundation for numerous studies to develop reliable and practical methods of inoculation $(1,2,4,10,24,29,31)$. These studies demonstrated that infection occurred most reliably after hypodermically injecting a suspension of sporidia into the wheat boot at, or slightly before, the awns emerging stage. However, infection using this technique does not relate to inoculum deposition and infection under natural conditions. The requirement of high relative humidity, which is critical for natural infection, is eliminated with this technique $(10,24)$. Inoculation of spikes at or near anthesis with a suspension of sporidia by either spraying, dipping, or vacuum-infiltrating spikes after emergence from the boot has been successful, but produced less disease than hypodermic injection into the boot $(3,10,24$, 29,31).

Studies with natural or artificial inoculation without boot injection report the growth stage that is most susceptible to infection is boot leaf (3), awns emerging (18), or the period when the spike is barely emerged from the boot (2). Numerous published statements and research results have reported that spikes are susceptible to natural infection during specific growth stages ranging from boot swelling to spike partially emerged $(18,27)$, boot stage to spike completely emerged (2), early boot stage to anthesis (25), between spike emergence and anthesis $(12,28)$, or during anthesis 
$(6,7,17)$. In some studies, inoculations after complete spike emergence or soon after anthesis successfully produced disease $(5,31)$, whereas in other studies, no disease was observed after inoculation at these stages $(2,18,29)$. In weather conditions that cause heavy dew or rain, it appears the boot leaf sheath and the flag leaf might be important for infection $(2,18)$.

The current study attempts to clarify wheat spike development stages that are susceptible to infection by $T$. indica, and to determine the stage of initial infection that causes the most damage, by using naturally liberated (16) and deposited secondary sporidia as inoculum during precise time intervals at several development stages.

\section{MATERIALS AND METHODS}

All work with Karnal bunt was performed with permits from the U.S. Department of Agriculture-Animal and Plant Health Inspection Service (USDA-APHIS)-Plant Protection and Quarantine and the Arizona Department of Agriculture. Karnal buntresistant and susceptible bread wheat cultivars, HD29 and WL711, respectively, were grown in 15 -cm-diameter pots in a greenhouse at the University of Arizona, Maricopa Agricultural Center. Seed of each cultivar was sown in 15 pots at 2- to 3-week intervals from October through November to provide a range of plant growth stages by March.

Teliospores from local sources of Karnal bunt near Phoenix, AZ, were surface-disinfested with $0.25 \% \mathrm{NaOCl}$ for $1 \mathrm{~min}$ followed by two brief rinses in sterile water, plated onto $2 \%$ water agar (Difco Bacto agar, Difco Laboratories, Detroit, MI), and incubated at $20^{\circ} \mathrm{C}$ for 6 days to germinate spores. Sporidia and hyphae from germination plates were cultured on $2 \%$ potato dextrose agar (PDA; Difco) at $20^{\circ} \mathrm{C}$. These were subcultured on PDA at $20^{\circ} \mathrm{C}$ for approximately 2 days to produce macroscopic colonies on the agar surface.

Six spikes from plants of each cultivar were selected at each of eight developmental stages ranging from Zadoks growth stage (GS) 49 to 85 (33): (i) awns emerging (GS 49); (ii) spike half emerged (GS 55); (iii) spike completely emerged before anthesis (GS 59); (iv) anthesis half completed (GS 65); (v) anthesis completed (GS 69); (vi) kernels watery ripe (GS 71); (vii) kernels at milk (GS 75); and (viii) kernels at soft dough (GS 85). The selected plants were moved into a walk-in growth chamber $(3.5$ by $5.0 \mathrm{~m}$ ) for inoculation and maintenance afterward as required by the work permit. The growth chamber supplied night/day temperatures of 16 and $27^{\circ} \mathrm{C}$, respectively, and $14 \mathrm{~h}$ of light per day from two 1,000-W metal halide bulbs and two 1,000-W sodium vapor bulbs placed in the middle of the chamber. Relative humidity was not controlled or monitored in the chamber, but it was estimated to be $<35 \%$.

Five spikes per cultivar and growth stage were inoculated immediately after moving plants to the growth chamber by laying plants in pots on their side and enclosing individual spikes (including the flag leaf for awns emerging and spike half emerged stages) in a chamber made of the bottom portions of 9-cm plastic petri dishes. To construct an inoculation chamber, the lid was removed from a fresh PDA pathogen culture described above and the culture was inverted over a spike placed on a new petri dish bottom lined with wet filter paper. A small notch was made in the side of the lower dish to accommodate the stem. Awns at the tip of spikes were clipped to fit the spike in the chamber. The chamber, with the spike enclosed, was held together with two pieces of tape on opposite sides of the dish; thus, it was not completely sealed. Spikes remained in the petri dish chambers for $43 \mathrm{~h}$ during which naturally liberated secondary sporidia (16) from the PDA cultures were deposited onto the spikes. One spike of each variety and growth stage was not inoculated to serve as a control. In addition, 15 pots each containing several uninoculated plants of cv. WL711 at boot to early spike emergence stages were inter- spersed among the inoculated plants during the inoculation and postinoculation plant growth periods to determine if inoculum capable of causing disease had spread from inoculated spikes.

To estimate the number of secondary sporidia deposited onto spikes during inoculation, a petri dish inoculation chamber was used to shower sporidia onto a glass microscope slide. The number of sporidia deposited on the slide after $30 \mathrm{~h}$ was estimated by counting the number of sporidia in 10 random $1.0-\mathrm{mm}$ squares on the microscope slide delimited with a hemacytometer placed beneath the slide. The total number counted on each slide was factored to account for a $1-\times 7-\mathrm{cm}$ area, which is similar to the size of a spike. Counts from four slides were taken and averaged.

Spikes were removed from inoculation chambers and left exposed to the relatively dry air in the growth chamber for 1 day and then were enclosed in glassine envelopes $(5 \times 20 \mathrm{~cm})$, as was required by the work permit. After inoculation, plants were placed in an area approximately $2 \times 2 \mathrm{~m}$ under the four lights in the middle of the growth chamber and grown to maturity. After spikes at the earliest growth stage started to lose chlorophyll due to maturation, the temperature was increased to a day and night cycle of 32 and $21^{\circ} \mathrm{C}$, respectively.

At maturity, spikes, still in glassine envelopes, were cut from plants, autoclaved to kill teliospores, and threshed by hand. Data were recorded for each kernel of each spike, including (i) position of the kernel in the spike, (ii) presence or absence of disease, and (iii) estimated severity of infection, i.e., percent conversion into a sorus. Minute point infections were verified by dissecting the sorus and microscopically examining a sample for mature teliospores. Fifty randomly selected spikes from uninoculated cv. WL711 plants interspersed among the inoculated plants during inoculation and growth were similarly harvested at maturity, bulked, hand threshed, and the seed was examined for disease. The experiment was performed during the 2002 to 2003 season and then repeated in 2003 to 2004.

For each cultivar and growth stage, percent infected kernels per spike (disease incidence) and the mean percent severity of kernel infection of diseased kernels per spike (kernel severity) were calculated. The mean kernel severity per spike was multiplied by percent disease incidence per spike to estimate how much of the total endosperm (including healthy kernels) of each spike was diseased (disease severity). Then, for the five spikes of each cultivar and growth stage, mean disease incidence per spike, mean kernel severity per spike, and mean disease severity per spike were calculated. Data for the three disease variables were arcsinesquare root-transformed and subjected to analysis of variance (ANOVA) separately for the two cultivars using a fixed model with the sources of variation being experiment, growth stage, replications within experiment, and growth stage $\times$ experiment (Table 1). Data from both experiments were combined subsequently, and means comparisons (least significant difference, $P=$ 0.05 ) were made between growth stages (JMP, SAS Institute, Cary, NC). Additionally, for disease severity, differences between cultivars at each growth stage were determined.

\section{RESULTS}

Plants grew well in the greenhouse producing the expected range of growth stages needed for the inoculations. Plants continued to grow during the 43-h inoculation period and spikes were slightly further developed than when first placed in the inoculation chambers. For example, some spikes initially at the awns emerging stage had boots that were split slightly, spikes initially half emerged were almost completely emerged, and some spikes initially at the emerged but not flowering stage had begun anthesis. During the inoculation period, the sporidial cultures on the PDA plates also continued to grow, and by the end of the inoculation period, white fungal colonies nearly covered the entire agar surface in the first experiment. In the second experiment, 
TABLE 1. Analysis of variance summaries of Karnal bunt data that resulted from inoculating spikes of susceptible and resistant wheat cvs. WL711 and HD29, respectively, at eight development stages with secondary sporidia of Tilletia indica ${ }^{\mathrm{w}}$

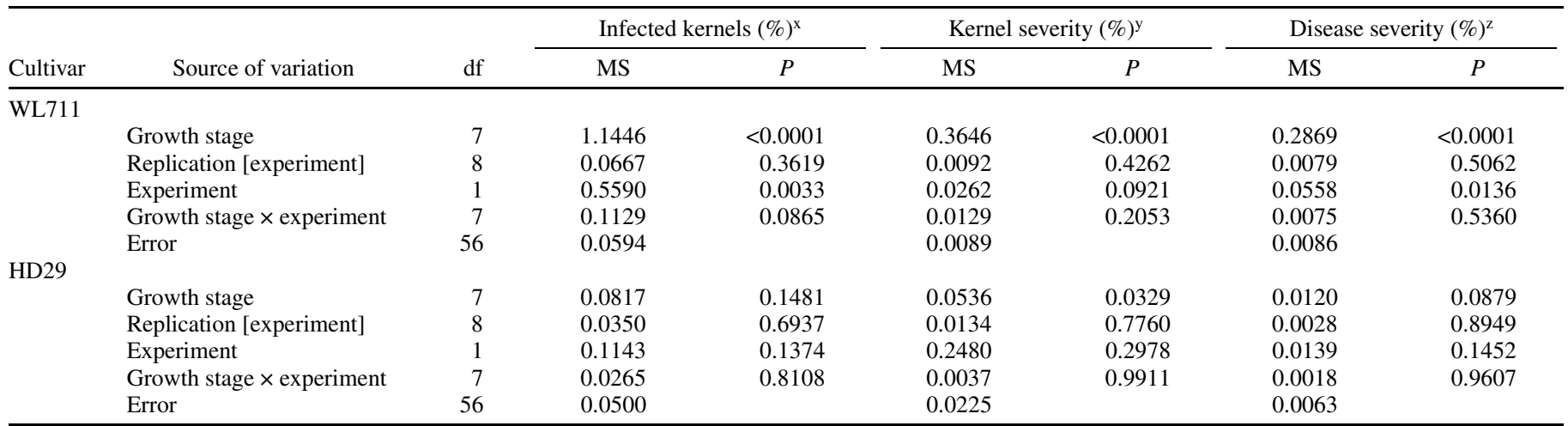

${ }^{\text {w }}$ Probability values based on arcsine-square root arcsine-transformed data.

${ }^{x}$ Mean percent infected kernels.

${ }^{y}$ Mean of the severity of infection of diseased kernels.

${ }^{\mathrm{z}}$ Average percent kernel severity of infected kernels per spike multiplied by percent infected kernels per spike to give a disease severity for each spike. Mean disease severity indicates how much of the total endosperm (including healthy kernels) was diseased at each growth stage.

TABLE 2. Mean Karnal bunt disease levels in susceptible and resistant wheat cvs. WL711 and HD29, respectively, inoculated with Tilletia indica at different spike development stages ${ }^{\mathrm{w}}$

\begin{tabular}{llccc}
\hline Cultivar & Growth stage & $\begin{array}{c}\text { Disease } \\
\text { incidence }(\%)^{\mathrm{x}}\end{array}$ & $\begin{array}{c}\text { Kernel } \\
\text { severity }(\%)^{\mathrm{y}}\end{array}$ & $\begin{array}{c}\text { Disease } \\
\text { severity }(\%)^{\mathrm{z}}\end{array}$ \\
\hline WL711 & & & \\
& Awns emerging & $0.0 \mathrm{e}$ & $0.0 \mathrm{~d}$ & $0.0 \mathrm{e}$ \\
& Head half emerged & $63.2 \mathrm{ab}$ & $13.3 \mathrm{~b}$ & $15.1 \mathrm{~b}$ \\
& Head emerged & $78.7 \mathrm{a}$ & $23.0 \mathrm{a}$ & $29.0 \mathrm{a}$ \\
& Half anthesis & $59.4 \mathrm{ab}$ & $9.6 \mathrm{~b}$ & $14.1 \mathrm{~b}$ \\
& Anthesis complete & $54.1 \mathrm{~b}$ & $8.1 \mathrm{~b}$ & $17.6 \mathrm{~b}$ \\
& Watery ripe & $30.6 \mathrm{c}$ & $2.6 \mathrm{c}$ & $6.5 \mathrm{c}$ \\
& Milk stage & $18.3 \mathrm{~cd}$ & $0.5 \mathrm{~cd}$ & $1.6 \mathrm{~d}$ \\
& Soft dough & $13.7 \mathrm{~d}$ & $0.3 \mathrm{~cd}$ & $1.0 \mathrm{~d}$ \\
& & & \\
& Awns emerging & $0.0 \mathrm{c}$ & $0.0 \mathrm{~b}$ & $0.0 \mathrm{c}$ \\
& Head half emerged & $10.6 \mathrm{ab}$ & $1.7 \mathrm{ab}$ & $4.2 \mathrm{abc}$ \\
& Head emerged & $14.2 \mathrm{a}$ & $2.3 \mathrm{a}$ & $8.4 \mathrm{a}$ \\
& Half anthesis & $6.9 \mathrm{abc}$ & $0.9 \mathrm{ab}$ & $2.5 \mathrm{abc}$ \\
& Anthesis complete & $5.2 \mathrm{abc}$ & $0.7 \mathrm{ab}$ & $6.3 \mathrm{ab}$ \\
& Watery ripe & $10.0 \mathrm{abc}$ & $0.5 \mathrm{~b}$ & $0.9 \mathrm{bc}$ \\
& Milk stage & $3.1 \mathrm{abc}$ & $0.1 \mathrm{~b}$ & $0.4 \mathrm{bc}$ \\
& Soft dough & $1.9 \mathrm{bc}$ & $0.0 \mathrm{~b}$ & $0.1 \mathrm{bc}$ \\
\hline
\end{tabular}

${ }^{\mathrm{w}}$ Means from each cultivar within the same column followed by the same letter are not significantly different based on means comparisons (LSD, $P=$ 0.05 ) using arcsine-square root transformed data.

$x$ Mean percent infected kernels of five spikes.

${ }^{y}$ Mean of the severity of infection of diseased kernels from five spikes at each growth stage.

$\mathrm{z}$ Average percent kernel severity of infected kernels per spike multiplied by percent infected kernels per spike to give a disease severity for each spike. Mean disease severity indicates how much of the total endosperm (including healthy kernels) was diseased at each growth stage.

the colonies on PDA exhibited less growth at the beginning and the end of the inoculation period, but had colonies that were macroscopically visible. Based on counts of sporidia naturally liberated from cultures inverted over glass microscope slides, approximately $2 \times 10^{5}$ sporidia were deposited over the area of each spike during the first $30 \mathrm{~h}$ of exposure in the first experiment. Sporidial counts were not taken in the second experiment.

As is common with Karnal bunt inoculations, there was considerable variation in the percentage of bunted kernels among the five spikes of each cultivar inoculated at different growth stages. Therefore, arcsine-square root transformation of percentage data based on infected kernels, kernel severity, and disease severity was applied. This transformation provided means with equal variances for cultivars inoculated at each growth stage.

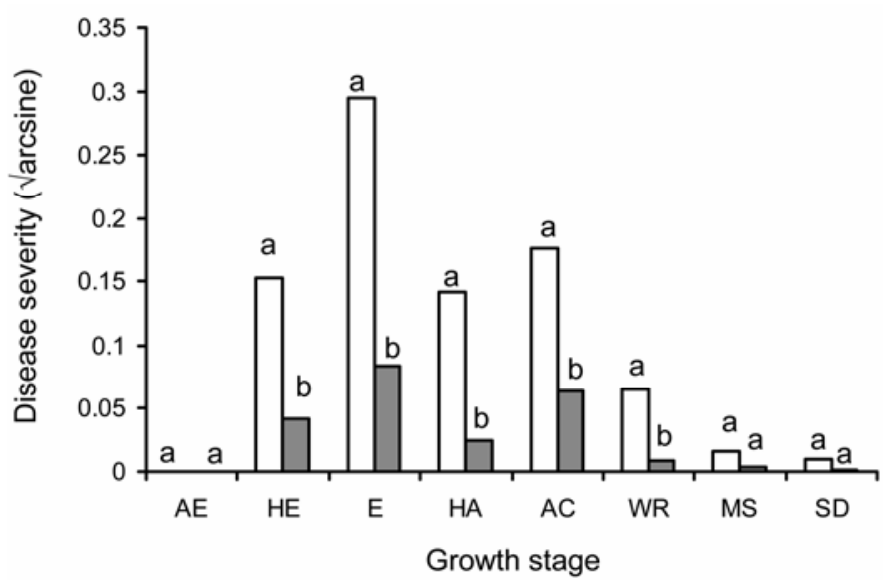

Fig. 1. Comparison of Karnal bunt disease severity of a susceptible (WL711, light bar) and a resistant (HD 29, shaded bar) wheat cultivar at eight spike development stages (AE, awns emerging; HE, spike half emerged; E, spike emerged before anthesis; HA, half anthesis; AC, anthesis complete; WR, watery ripe; MS, milk stage; and SD soft dough) after inoculating spikes with secondary sporidia of Tilletia indica. Disease severities at each stage followed by the same letter are not significantly different $(P=0.05)$.

Analysis based on the susceptible cultivar (WL711) indicated that growth stage was the most significant source of variation for all three disease measurements (Table 1). Additionally, lower disease pressure in the second experiment, likely due to more limited inoculum growth, caused the effect of experiment to be significant for infected kernels and kernel severity (Table 1). ANOVA of the resistant cultivar (HD29) indicated that growth stage was the only source of significant variation for disease severity (Table 1). Based on these analyses, data from the two experiments were combined prior to means comparison.

Infection occurred in both cultivars at all growth stages tested except awns emerging (Table 2). There were no diseased kernels in the uninoculated control spikes or in the 50 uninoculated spikes harvested from cv. WL711 plants interspersed among inoculated plants. Disease incidence, kernel severity, and disease severity peaked in both cultivars after inoculations at complete spike emergence, but before the beginning of anthesis (Table 2). At this stage, cv. WL711 had up to $79 \%$ bunted kernels, a kernel severity of $23 \%$, and a disease severity of $29 \%$, of which disease severity and kernel severity were significantly higher than at all other stages (Table 2). All three disease measurements tapered off 
gradually as spikes matured to soft dough stage (Table 2). For unexplained reasons, infection of cv. HD29 at the watery ripe stage produced a fairly high percentage of bunted kernels in the first experiment; however, this effect was not statistically significant (Table 2). Although the percentage of infected kernels was relatively high in both cultivars inoculated at milk and soft dough stages, only a small proportion of the kernel was converted into a sorus. The same growth stage-related trends in disease severity occurred in both cultivars (Fig. 1). As was expected, lower disease severity occurred in resistant cv. HD29 than in susceptible cv. WL711, but the differences were not significant after inoculations at milk and soft dough stages (Fig. 1).

There were no clear patterns relative to the location of infected kernels within spikes of either cultivar at any given stage (data not shown). For example, physiologically less advanced florets at the tip and base of the spike, or more advanced florets near the center of spikes, were not obviously more or less susceptible to infection at any given stage of inoculation.

\section{DISCUSSION}

The results presented here demonstrated for the first time that under nearly ideal conditions for infection, Karnal bunt can develop after initial inoculation of spikes at growth stages as late as milk and soft dough to produce a fairly high percentage of bunted kernels. In the only other study (2) that has examined infection after postanthesis inoculations, termed "slight grain formation" (which likely represented the watery ripe stage), no infection occurred. The work of Dhaliwal et al. (11) indicates that secondary systemic infection can occur as late as dough stage in spikes, but it occurs only after the fungus is already well established in adjacent spikelets from infection at earlier growth stages.

Numerous studies using hypodermic injection to deliver inoculum into the boot before spike emergence have demonstrated that florets within the boot are in a susceptible state before emergence $(1,2,4,10,24,29,31)$. However, this does not relate to natural inoculum deposition and infection, since spikes are enclosed within the boot where airborne inoculum cannot reach the glumes where hyphal penetration is initiated (14). The results presented here demonstrated that when naturally deposited inoculum is present only prior to emergence of the spike, infection did not occur even under very high disease pressure. This is inconsistent with claims of susceptibility to naturally deposited inoculum prior to spike emergence $(3,18,27)$. It seems possible that spray, dip, or natural inoculum delivery at the boot stage in other studies $(2,3$, 18) may have provided inoculum that remained viable until spikes emerged from the boot and then caused infection. In the present study, sporidia on inoculated plants likely desiccated rapidly after being removed from inoculation chambers preventing infection at later stages. This is evidenced by the lack of infection in the uninoculated control plants at different stages, and in cv. WL711 plants that were interspersed among inoculated plants during and after inoculations. It has been reported that secondary sporidia are incapable of growth at relative humidity of $<70 \%$ (28) and lose viability rapidly at relative humidity $<50 \%(30)$.

The results of this study confirmed other studies using artificial (30) or natural inoculation (5) that resulted in substantial disease development at plant development stages at or just beyond flowering. The results here are inconsistent with those studies that have shown slight or no infection after natural (18) or artificial inoculation (2) at these stages.

It was surprising to find there was sufficient time to induce disease by inoculation at the soft dough stage. The high disease pressure in these experiments would be very rare under natural conditions. However, it appears that low levels of disease that have been problematic from a quarantine perspective could be induced under natural field conditions when sufficient disease pressure occurs long after anthesis, and perhaps even up to soft dough stage.

Although the hard dough stage was not inoculated in the current experiment, it seems unlikely disease would have been induced because shortly after this stage the glumes begin to senesce and systemic fungal growth would likely be difficult. Also, it is doubtful whether there would be sufficient time for the fungus to infect the floret, reach and establish itself in the periderm of the kernel, and complete teliosporogenesis before kernel maturation stopped the process. There was barely sufficient time for a sorus to develop after inoculations at the soft dough stage in these experiments as evidenced by the slight levels of kernel infection.

Under normal field conditions, it takes approximately 35 days for an individual wheat spike to pass through the susceptible period of spike emergence to soft dough stages as determined in this study. This period is extended further within any given field by the presence of early and late tillers. For an individual spike, the highest risk of infection occurs over a period of approximately 12 days during which the spike emerges and progresses to the completion of anthesis. This information should allow a more precise assessment of the risk of infection during spike development and enable improved disease management decisions.

\section{ACKNOWLEDGMENTS}

We thank G. Lane (USDA-ARS, Maricopa, AZ) for growing and maintaining the plants used for these experiments, and R. Ykema (Arizona Department of Agriculture) and T. Boratynski (USDA-APHIS) for assistance with inoculum production.

\section{LITERATURE CITED}

1. Aujla, S. S., Grewal, A. S., Gill, K. S., and Sharma, I. 1982. Artificial creation of Karnal bunt disease of wheat. Cereal Res. Comm. 10:171-176.

2. Aujla, S. S., Sharma, I., and Gill, K. S. 1986. Effect of time and method of inoculation on Karnal bunt development. Indian Phytopathol. 39:230233.

3. Bains, S. S. 1994. Influence of wheat spikes maturity on susceptibility to infection and growth of sporidia of Neovossia indica. Indian J. Mycol. Plant Pathol. 24:111-115.

4. Bains, S. S., and Dhaliwal, H. S. 1990. Production of Neovossia indica sporidia on host and non-host plants. Plant Soil 126:85-89.

5. Bedi, K. S., Sikka, M. R., and Mundkur, B. B. 1949. Transmission of wheat bunt due to Neovossia indica (Mitra) Mundkur. Indian Phytopathol. 2:20-26.

6. Bonde, M. R., Peterson, G. L., Schaad, N. W., and Smilanick, J. L. 1997. Karnal bunt of wheat. Plant Dis. 1370-1377.

7. Bonde, M. R., and Smilanick, J. L. 1998. Life cycle and environmental requirements of Tilletia indica. Pages 137-148 in: Bunts and Smuts of Wheat: An International Symposium. V. S. Malik and D. E. Mathre, eds. North American Plant Protection Organization, Ottawa.

8. Brennan, J. P., Warham, E. J., Hernandez, J., Byerlee, D., and Doronel, F. 1990. Economic losses from Karnal bunt of wheat in Mexico. CIMMYT Economics Working Paper 90/02. CIMMYT, Mexico, DF.

9. Cashion, N. L., and Luttrell, E. S. 1988. Host-parasite relationships in Karnal bunt of wheat. Phytopathology 78:75-84.

10. Chona, B. L., Munjal, R. L., and Adlakha, K. L. 1961. A method for screening wheat plants for resistance to Neovossia indica. Indian Phytopathol. 14:99-101.

11. Dhaliwal, H. S., Randhawa, A. S., Chand, K., and Singh, D. 1983. Primary infection and further development of Karnal Bunt of wheat. Indian J. Agric. Sci. 53:239-244.

12. Fuentes-Davila, G. 1998. Karnal bunt of wheat. Pages 69-81 in: Bunts and Smuts of Wheat: An International Symposium. V. S. Malik and D. E. Mathre, eds. North American Plant Protection Organization, Ottawa.

13. Gill, K. S., Sharma, I., and Aujla, S. S. 1993. Karnal Bunt and Wheat Production. Punjab Agricultural University, Ludhiana.

14. Goates, B. J. 1988. Histology of infection of wheat by Tilletia indica, the Karnal bunt pathogen. Phytopathology 78:1434-1441

15. Goates, B. J. 1996. Common bunt and dwarf bunt. Pages 12-25 in: Bunt and Smut Diseases of Wheat: Concepts and Methods of Disease Management. R. D. Wilcoxin and E. E. Saari, eds. CIMMYT, Mexico, DF.

16. Goates, B. J., and Hoffmann, J. A. 1986. Formation and discharge of secondary sporidia of the bunt fungus, Tilletia foetida. Mycologia 78:371379. 
17. Joshi, L. M., Singh, D. V., Srivastava, K. D., and Wilcoxson, R. D. 1983. Karnal bunt: A minor disease that is now a threat to wheat. Bot. Rev. 49:309-330.

18. Kumar, J., and Nagarajan, S. 1998. Role of flag leaf and spike emergence stage on the incidence of Karnal bunt in wheat. Plant Dis. 82:1368-1370.

19. Mitra, M. 1931. A new bunt of wheat in India. Ann. Appl. Biol. 18:178179.

20. Mitra, M. 1935. Stinking smut (bunt) of wheat with special reference to Tilletia indica Mitra. Indian J. Agric. Sci. 1:51-74.

21. Mundkur, B. B. 1943. Studies in Indian cereal smuts V. Mode of transmission of the Karnal bunt of wheat. Indian J. Agric. Sci. 13:54-58.

22. Mundkur, B. B. 1943. Karnal bunt, an air-borne disease. Curr. Sci. 12:230-231.

23. Poe, S. 1998. APHIS response to Karnal bunt prior to March 1996. Pages 107-111 in: Bunts and Smuts of Wheat: An International Symposium. V. S. Malik and D. E. Mathre, eds. North American Plant Protection Organization, Ottawa.

24. Royer, M. H., and Rytter, J. 1985. Artificial inoculation of wheat with Tilletia indica from Mexico and India. Plant Dis. 69:317-319.

25. Rush, C. M., Stein, J. M., Bowden, R., Riemenschneider, R., Boratynski, T., and Royer, M. H. 2005. Status of Karnal bunt of wheat in the United States 1996 to 2004. Plant Dis. 89:212-223.
26. Sekhon, K. S., Singh, N., and Singh, R. P. 1992. Studies on the improvement of quality of wheat infected with Karnal bunt. I. Milling, rheological, and baking properties. Cereal Chem. 69:50-54.

27. Sharma, A. K., Kumar, J., and Nagarajan, S. 1998. Worldwide movement of smuts and bunts. Pages 129-135 in: Bunts and Smuts of Wheat: An International Symposium. V. S. Malik and D. E. Mathre, eds. North American Plant Protection Organization, Ottawa.

28. Singh, A. 1994. Epidemiology and management of Karnal bunt disease of wheat. Directorate of Experiment Station, G.B. Plant University of Agriculture and Technology, Res. Bull. No. 127.

29. Singh, R. A., and Krishna, A. 1982. Susceptible stage for inoculation and effect of Karnal bunt on viability of wheat seed. Indian Phytopathol. 35:54-56.

30. Smilanick, J. L., Prescott, J. M., Hoffmann, J. A., Secrest, L. R., and Weise, K. 1989. Environmental effects on survival and growth of secondary sporidia and teliospores of Tilletia indica. Crop Prot. 8:86-90.

31. Warham, E. J. 1990. A comparison of inoculation techniques for assessment of germplasm susceptibility to Karnal bunt (Tilletia indica) disease of wheat. Ann. Appl. Biol. 116:43-60.

32. Ykema, R. E., Floyd, J. P., Palm, M. E., and Peterson, G. L. 1996. First report of Karnal bunt of wheat in the United States. Plant Dis. 80:1207.

33. Zadoks, J. C., Chang, T. T., and Konzak, C. F. 1974. A decimal code for growth stages of cereals. Weed Res. 14:415-421. 